\section{DIZER-MOSTRAR O ESTRANHO}

SAYING-SHOWING STRANGENESS

\section{Helena Martins}

PUC-Rio

Rio de Janeiro, RJ, Brasil

\title{
Resumo
}

Este trabalho explora a vitalidade contemporânea de duas enfáticas vozes do século XX: Ludwig Wittgenstein e Samuel Beckett. Consideram-se em especial as seguintes divisas: de Wittgenstein, NADA ESTÁ OculTO (Investigaçôes, $\$ 435$ ); de Beckett, NADA A EXPRESSAR (Três diálogos com George Duthuit, I). O dito de Wittgenstein é muitas vezes tomado como marca de renúncia à distinção, por ele antes sustentada, entre aquilo que se pode dizer e aquilo que apenas se mostra (Tractatus, Prefácio, 6.522). O dito de Beckett é, por sua vez, frequentemente visto como indício de uma visão cética da linguagem, que a condena a uma espécie de maldição da autorreferência. Tais formas de ler tendem a se ligar às percepções, bastante disseminadas, de que Wittgenstein escreve o comum (o "ordinário"); e Beckett, o absurdo. Questiono aspectos dessas duas produtivas leituras, sustentando que, de forma a meu ver um pouco debilitante, elas tendem a ignorar, ou talvez a apaziguar, um estranho que insiste em se dizer-mostrar na prosa poética dos dois autores.

\section{Abstract}

This paper explores the contemporary strength of two of last century's most emphatic voices: Ludwig Wittgenstein and Samuel Beckett. The following mottos are brought together with special attention: NOTHING IS HIDDEN, by Wittgenstein (Philosophical Investigations, $\$ 435)$; and NOTHING TO EXPRESS, by Beckett (Three dialogues with Georges Duthuit, I). Wittgenstein's saying is frequently taken as indication that he renounces his earlier distinction between what can be said and what can only be shown (Tractatus, Preface, 6.522). Beckett's saying is, in turn, often seen as evi-

\section{Résumé}

Cet article explore la vitalité contemporaine de deux voix emphatiques du XXe siècle: Ludwig Wittgenstein et Samuel Beckett. Nous rassemblons ici en particulier les deux devises suivantes: de Wittgenstein, RIEN N'EST CACHÉ (Investigations philosophiques, \$435); de Beckett, RIEN À EXPRIMER (Trois Dialogues, I). Le dicton de Wittgenstein est souvent considéré comme une indication qu'il renonce à son ancienne distinction entre le dire et le montrer (Tractatus, Préface, 6522). La phrase de Beckett, à son tour, est souvent considérée comme marque d'une vision sceptique du langage,
PALAVRAS-CHAVE: Wittgenstein; Beckett; dizer e mostrar; estranho.

KEYWORDS: Wittgenstein; Beckett; saying and showing; strangeness.

MOTS-CLÉS: Wittgenstein; Beckett; dire et montrer; étrangeté. 
dence of a skeptical take on language, whereas it is, so to speak, doomed to self-reference. These interpretations tend to be linked to the widespread perceptions that Wittgenstein writes the ordinary, whereas Beckett writes the absurd. I question some aspects of these two productive readings, arguing that, in a somewhat debilitating manner, they tend to ignore, or perhaps pacify, a strangeness that insists in saying-showing itself in the poetic prose of both authors. qui la condamne à une sorte de malédiction d'autoréférence. Ces interprétations ont tendance à être liées à des perceptions communes selon lesquelles Wittgenstein écrit l'ordinaire, tandis que Beckett écrit l'absurde. Je m'interroge sur certains aspects de ces deux lectures fertiles, faisant valoir que, d'une manière quelque peu débilitante, ils ont tendance à ignorer, ou peut-être à apaiser, une étrangeté qui insiste à se dire-montrer dans la prose poétique des deux auteurs.
*(WITTGENSTEIN, Ludwig Investigações Filosóficas. Trad. José C. Bruni. São Paulo: Nova Cultural, 1999: \$435; BECKETT, Samuel. "Três diálogos com George Duthuit". Trad. Fabio S. Andrade. In: _. Samuel Beckett: o silêncio possivel. São Paulo: Ateliê Editorial: 175.$)$

Duas divisas provocam (e ameaçam interditar) este texto:

Nada está oculto

Nada a expressar

A primeira foi escrita por Ludwig Wittgenstein; a segunda, por Samuel Beckett.* A atenção que lhes dou aqui é movida por um interesse geral em explorar o vigor contemporâneo dessas duas enfáticas vozes do século passado - e por um desejo particular de escutá-las ao mesmo tempo.

Escuta-se primeiro nos dois casos, é provável, um tom reativo.

Com seu "nada está oculto", Wittgenstein reage, já se sabe, à busca compulsiva de um por trás que, para ele e para tantos outros filósofos do nosso tempo, marcou desde o princípio a história da metafísica no Ocidente: a compulsão de buscar por trás da aparência uma essência; por trás do corpo um espírito; por trás da palavra um sentido - por trás de cada fora um dentro escondido. Contra essa propensão, Wittgenstein insiste: nada há por revelar, pois nada está oculto. O único mistério das coisas, ele diria talvez com Caeiro, é elas não terem mistério nenhum.

Por sua vez, com seu "nada a expressar", dito que comparece nessa difícil ficção pensante que são os "Três diálogos com Georges Duthuit", Beckett reage também: agora a uma propensão onipresente na história da literatura e das artes, a sua ambição expressiva. Explicita, a certa altura, sua desavença, declarando-se "cansado de 
fingir-se capaz, de ser capaz, de fazer um pouco melhor a mesma velha coisa, de trilhar um pouco mais a velha terrível estrada".* Duthuit pergunta então a Beckett sobre o caminho alternativo que preferiria, ao que este responde com sua célebre e ritmada cadeia aporética: “[a] expressão de que não há nada a expressar, nada com que expressar, nada a partir do que expressar, nenhuma possibilidade de expressar, aliado à obrigação de expressar". * Afirma sonhar com uma "arte inexpressiva", uma arte "que não lamente a sua insuperável indigência e que seja orgulhosa demais para a farsa do dar e do receber".*

As duas conhecidas divisas - nada está oculto, nada a expressar-recebem com alguma recorrência entre os frequentadores dos textos de Wittgenstein e de Beckett um certo tipo de interpretação que vejo como debilitante sob alguns aspectos, mesmo quando revigorante sob outros. Penso que sua debilidade talvez resida em serem leituras que ignoram ou pelo menos amortecem um estranho, ou a potência de um estranho, capaz de insistir a meu ver, ainda hoje, nas escritas dos dois autores. Uma versão preliminar deste trabalho foi de fato apresentada em um simpósio sugestivamente intitulado Estranhamento hoje. No curso das discussōes que ali tiveram lugar, somou-se com frequência à marca do tempo - hoje - uma interrogação de modo - como? Como (ainda) um estranhamento hoje? ${ }^{1}$ Exploro aqui a possibilidade de que uma atenção renovada e conjunta a Wittgenstein e Beckett, autores de outro século, catalise alguma coisa na esfera dessa interrogação.

Parece-me, nesse sentido, especialmente oportuno revisitar e periclitar aqui duas percepçôes tão disseminadas quanto, a meu ver, propensas ao amortecimento acima aludido: Wittgenstein escreve o comum (o "ordinário"); Beckett, o absurdo. Nada está oculto: um supraordinário não comparece; tudo bem à vista, portanto, no terreno do ordinário. Nada a expressar: a não ser a inexpressividade e o absurdo de tudo.

Para indicar o modo como essas produtivas formas de ler podem, por outro lado, servir a uma (para mim indesejável) rare-

\footnotetext{
${ }^{1}$ Simpósio organizado por Myriam Ávila, Sérgio Luiz Medeiros e Caetano Galindo, no XII Congresso da ABRALIC, 2011. No texto que apresentava o simpósio, já se lia, por exemplo: "Um novo estranho? A prosaificação, a quotidianificação de todo estranhamento possível?” Em: XII Congresso Internacional da ABRALIC. Disponível em: http://www.abralic.org.br/upload/informativo/simposiosaprovados.pdf (acesso em 03/11/2011).
} 
*(WITTGENSTEIN, Ludwig. Da certeza. Trad. Maria E. Costa. Lisboa: Edições 70, 1969: §559.)

* (BECKETT, Samuel. O inominável. Trad. Maria J. V. de Figueiredo. Lisboa: Assírio \&. Alvim, 2002: 148.)
* (WITTGenstein, Ludwig. Wittgenstein's lectures - Cambridge, 19301932: from the notes of John King and Desmond Lee. D. Lee (ed.). Oxford: Basil Blackwell, 1980: 112.)

* (BECKETT, Samuel. O inominável. Trad. Maria J.V. de Figueiredo. Lisboa: Assírio \&. Alvim, 2002: 183.) fação do estranho, começo lembrando um vetor comum às escritas de Beckett e de Wittgenstein - sua conhecida insistência em paisagens que dão a ver o sem fundo da linguagem. Duas ocasiōes bem explícitas e muito citadas:

Você deve ter em conta que o jogo da linguagem é, por assim dizer, imprevisível. Quero dizer: não se baseia em fundamentos. Não é razoável (ou irrazoável).

Está aí - tal como a nossa vida.*

[...] sou de palavras, sou feito de palavras, das palavras dos outros, que outros, e o lugar também, o ar também, as paredes, o chão, o teto, o universo está todo aqui, comigo, sou o ar, as paredes, o emparedado, tudo cede, tudo se abre, anda à deriva, recua, flocos, sou estes flocos todos, que se cruzam, se unem, se separam [...] palavras, sou todas essas palavras, todos estes estranhos, esta poeira de verbo, sem fundo onde pousar, sem um céu para se dissipar [...].*

$\mathrm{Na}$ raiz da busca incessante de um por trás oculto, supostamente resistente à expressão verbal - busca da essência por trás da aparência, busca do absoluto por trás da dispersão fenomênica etc. -, na raiz dessa busca estaria uma percepção tão imperiosa quanto equivocada da linguagem: uma crença, refutável intelectualmente mas persistente como superstição, na ideia de que a linguagem funciona como um sistema de representação, como uma espécie de invento fundado na razão, artefato controlável, manipulável e apto a referir-se a um "fora" - as coisas, o pensamento, o eu.

Wittgenstein e Beckett, assim como tantos outros filósofos e artistas do nosso tempo, convidaram-nos a reconhecer na linguagem, muito ao contrário, um conjunto de práticas históricas voláteis, descontínuas e irredutíveis a qualquer sistema fixo e atemporal, práticas que não representam mas antes forjam em larga medida as nossas sempre provisórias partições: ontológicas, psicológicas, éticas, estéticas, e assim por diante. Convidaram-nos, enfim, a reconhecer que a linguagem "não é contígua ao que quer que seja"* que não tem propriamente, portanto, um dentro e um fora, uma superfície e um fundo: "lá fora, cá dentro, só há este lugar", * lugar de palavras sem centro de gravidade.

Nada disso é novo, sobretudo se tomado às pressas. Aos que toleraram até este ponto a repetição, perguntaria, no entanto: a sedimentação contemporânea dessa perspectiva, sua conversão em dialeto corrente em muitos círculos intelectuais (e na minha própria boca), não terá alguma relação com a antes aludida dificuldade de 
entrever ainda hoje a possibilidade do estranhamento, a chance de se experimentar em sua vivência ainda alguma (promissora) vertigem? Quando o discurso sobre o sem fundo se acostuma em um linguajar, não se pacifica a ponto de ameaçar tornar-se um paradoxal neo-fundo? Creio que os textos de Wittgenstein e de Beckett a um tempo se prestam e resistem a esses impulsos (paradoxalmente nostálgicos?) de pacificação. Interesso-me aqui pela resistência.

Beckett escreve o absurdo. Para quem quer que o tenha lido, isso faz, é claro, instantâneo sentido: parecerá óbvia e imediata, por esse ângulo, a associação entre sua escrita e o estranho. Gostaria, no entanto, de reconhecer nessa imediatez da evocação do absurdo e do estranho o seu próprio enfraquecimento, a sua própria debilidade. É uma imediatez que se reforça e se precipita sob o peso de um substantivo classificador, já bem assentado na história: Beckett teria sido um absurdista. Convertido em categoria, domesticado como verbete, o estranho se enfraquece. Em conversa com Charles Juliet, Beckett, que, como se sabe, nunca reconheceu filiação ao chamado teatro do absurdo, resiste:

"É absurdo dizer que algo é absurdo. Isso ainda é um juízo de valor. É impossível protestar tanto quanto é impossível assentir."

Depois de uma longa pausa:

"É preciso trabalhar numa área em que não haja pronomes ou soluções ou reações ou pontos de vista possíveis - é isso que torna tudo tão diabolicamente difícil."*

Se tomada juntamente com essas palavras, com alguma sorte, a divisa "nada a expressar" não será reação intelectual, solução, ponto de vista. E a palavra "nada” tampouco será propriamente o precário pronome substituto de um inefável qualquer, de um escuro ou vazio por expressar. A frase será talvez melhor recebida - como disse certa vez Agamben sobre o "I would prefer not to" de Bartleby* - como ato, como declaração performativa de um evento: sob esse ângulo, se há em "nada a expressar" uma declaração, declara-se aqui talvez mais como se declara guerra ou greve ou independência etc.: não se trata (tanto?) do logos apophantikos aristotélico - de uma declaração expressiva, que, candidata a um valor de verdade, descreve um estado de coisas.

Renunciar, porém, à ambição expressiva é, Beckett admite, diabolicamente difícil. E igualmente difícil é renunciar a ler Beckett sem ceder à farsa do dar e do receber: o que ele estaria tentando
* (JULIET, Charles; BECKETT, Samuel. Conversations with Samuel Beckett and Bram van Velde. Leiden, Netherlands: Academic Press, 1995: 165. Tradução minha, aqui e em todas as demais citações sem outra indicação.)

* (AGAMBEN, Giorgio. Bartleby-a escrita da potência. Trad. M. Rodrigues e P. H. Paixão. Lisboa: Assírio e Alvim, 2007: 29 et seq.) 
*(WITTGENSTEIN, Ludwig. Investigações Filosóficas. Trad. José C. Bruni. São PauIo: Nova Cultural, 1999: II 165.)

* (Cf. BAIR, Deirdre. Samuel Beckett: a biography. London: Jonathan Cape, 1978: 528.)

* (WITTGENSTEIN, Ludwig, op. cit.: \$245.) expressar com o seu "nada a expressar"? Talvez o diabo - este que, como Rosa nos ensinou, não existe e por isso é tão forte -, talvez o diabo de Beckett sorria lá no inferno quando ouve, por exemplo, quem diga que na sua escrita as palavras se referem somente a elas mesmas, estando aí o grande estranho, o grande absurdo que ele logra denunciar: nada a expressar a não ser a própria falência expressiva da linguagem, sua natureza puramente autorreferencial. ${ }^{2}$ Pois decretar esse tipo de falência seria ainda uma forma de ceder à diabólica tentação de ver na linguagem um telos: referir. Não tendo êxito em referir-se a um fora, ela se dobraria sobre si mesma - mantendo-se assim, no entanto, fiel ao registro da referência. Reduzida ainda à conhecida vocação referencial, a linguagem autorreferente não nos é assim tão estranha: pacifica-se como uma espécie de maldição ou de prisão bem discernida - sem surpresas.

A escrita de Beckett promete, a meu ver, persistir num estranho mais radical, no qual a linguagem, sem telos, sem ser a forma de um conteúdo, mesmo que de um vazio, resiste a reificar-se, a deixar-se abstrair de nossa "complicada forma de vida", para usar a expressão apta de Wittgenstein, * aqui, creio, em sintonia possível com Beckett.

"Se você insiste em encontrar uma forma" para minhas peças, disse certa vez Beckett a Harold Pinter, "então eu a descrevo para você: estava uma vez no hospital; havia um homem em outro leito, morrendo de câncer na garganta - nos silêncios, eu ouvia seus gritos continuamente; esse é o único tipo de forma que o meu trabalho tem".* Em tom e fervor semelhantes, ouvimos de Wittgenstein: "como posso, pois, querer colocar ainda a linguagem entre a manifestação da dor e a dor?"* Nos dois casos, o que se desconvida radicalmente não é apenas a dicotomia entre forma e conteúdo, a expressão e o expresso; é sobretudo uma apreensão da linguagem como um algo abstraído da vida, como camada ontologicamente autônoma, que separa-comunica um exterior e um interior (plenos ou vazios). E se a linguagem é, não um algo, mas antes uma forma de vida, e se, como Beckett tantas vezes parece insistir, ela falha, o

${ }^{2}$ Esse vetor interpretativo é bastante conhecido. Um exemplo metonímico: “em Beckett, o hiato entre a linguagem e a realidade mostra-se como intransponível [...]; a linguagem não pode dar mostras certas de nada, a não ser de si própria, estabelecendo então uma referência direta à sua própria artificiosidade" (MAGARIT, Lucas. Samuel Beckett: las huelas en el vacío. Madrid, Buenos Aires: Editorial La Avispa S. L. \& Atuel, 2003: 89). 
que (estranhamente?) falha é a vida. E o "nada a expressar", paradoxalmente aliado à obrigação de expressar, será talvez mais grito que descrição - não será em todo caso, se possível, como disse o próprio Beckett certa vez, "uma declaração ou uma descrição do calor do espírito para compensar o pus do espírito".*

Aqui poderíamos entreouvir um desacordo entre Beckett e Wittgenstein, convivendo com a ênfase, por eles compartilhada, na linguagem como forma de vida irredutível a qualquer telos: Wittgenstein pareceria desaver-se com essa insistência da Beckett na "desgraça da linguagem".* Pois, em sua investida vigorosa contra os filósofos que desejaram expurgar a língua comum de suas supostas imperfeições, em benefício de uma linguagem ideal, Wittgenstein famosamente protestou: "Mas está tudo certo com a linguagem comum". * Sob a força dessa convicção, seu "nada está oculto" dá testemunho de uma confiança na linguagem que parece de fato, pelo menos a princípio, afastá-lo do universo beckettiano. Se há contudo uma dissonância aqui (creio que há), ela é mais sutil do que óbvia, dificilmente se configurará como a diferença trivial entre os tons do otimismo e do pessimismo. É mais complicado.

Para que se possa compreender melhor o que está em jogo, vale a pena cercar a ideia de que Wittgenstein escreve o comum (o ordinário) de cuidados semelhantes aos que dispensamos à ideia, até certo ponto simétrica, de que Beckett escreve o absurdo: tanto quanto o absurdo em Beckett, esse comum em Wittgenstein, se lido de certo modo bastante disseminado, candidata-se a indesejável instrumento de domesticação. Prefiro compreender o ordinário wittgensteiniano na companhia de leitores que, não por acaso, afastando-se da tradição dita analítica, souberam escutar com atenção as seguintes palavras do filósofo: "penso que resumi minha atitude quando disse: a filosofia deveria escrever-se como composição poética".*

Falo sobretudo de Stanley Cavell e Marjorie Perloff, autores que reconheceram e sublinharam na escrita Wittgenstein precisamente os modos como ela dá a ver-poeticamente - a estranheza do comum. ${ }^{3}$ Creio, com eles, que Wittgenstein, assim como Beckett,

\footnotetext{
${ }^{3}$ Trata-se de um tema recorrente nas obras de Cavell e Perloff, frequentando inclusive os títulos de seus escritos (CAVELL, Stanley. "The uncanniness of the ordinary". In The Quest of the Ordinary. Chicago: The University of Chicago Press, 1988; PERLOFF, Marjorie. Wittgenstein's Ladder: the Strangeness of the Ordinary. Chicago: The University of Chicago Press, 1996). É oportuno mencionar que,
}

* (BECKETT, Samuel. Carta a T. McGreevy, 18/10/32. In: The Letters of Samuel Beckett: 1929-1940. M. D. Fehsenfeld, L. M. Overback (eds.). London: Cambridge University Press, 2009: 134.)

* (BECKETT, Samuel. Carta a A. Kaun, 09/07/1937, op. cit.: 518.)

*(WITTGENSTEIN, Ludwig The Blue and Brown Books. New York: Harper \& Row, 1965: 28.)

* (WITTGENSTEIN, Ludwig. Cultura e valor. Trad. J. Mendes, Lisboa: Edições 70, 1996: 24.) 
* (CAVELL, Stanley, op. cit.: 154.)

*(WITTGENSTEIN, Ludwig. Tractatus Logico-Philosophicus. Trad. Luiz H. L. dos Santos. São Paulo: EDUSP, 1994: $4.1212,181$.) escreve ou busca escrever (entre outras coisas) o comum-estranho: sua claro-escura irredutibilidade. Segundo Cavell, essa estranheza do comum estaria "na capacidade, e mesmo no desejo, que a linguagem ordinária tem de repudiar-se a si mesma"**

Talvez porque tenham permanecido cegos para essa estranha capacidade, muitos dos leitores de Wittgenstein afirmaram que desaparece de sua filosofia madura a tensão que ele de início sustentara existir entre o que se pode dizer e o que apenas se pode mostrar. Assim como a já aludida propensão a ler na escrita de Beckett um monotemático ceticismo linguístico, a tendência a negar qualquer sobrevida para o jogo entre dizer e mostrar no pensamento maduro de Wittgenstein pode ser sintoma de uma rarefação do estranho - ou pelo menos de uma atenção insuficiente ao insólito capaz de insistir em sua escrita (do) comum e também em sua divisa "nada está oculto".

Não cabe aqui, é claro, uma discussão exegética sobre a evolução do pensamento de Wittgenstein. Interessa, no entanto, pensar se e como uma tensão entre dizer mostrar ainda pode ter lugar quando se toma radicalmente a linguagem como práxis, como forma de vida - caso de Wittgenstein e também de Beckett, segundo a leitura que proponho aqui.

Nas linhas de seu Tractatus, linhas que, como se sabe, caíram sob a mira de sua própria crítica demolidora posterior, Wittgenstein tinha com efeito estabelecido uma distinção entre aquilo que se pode dizer e aquilo que, inefável, apenas se mostra: "o que pode ser mostrado não pode ser dito".* Naquele momento, Wittgenstein sustentava explicitamente que estariam incluídos no domínio daquilo que se mostra mas não se diz, entre outras coisas, a ética, a estética e a religião. Muitos dos seus mais renomados leitores acreditam de fato que essa dimensão de um indizível, um inefável que se mostra sem se deixar dizer, desaparece de sua segunda filosofia. ${ }^{4}$ E com alguma razão.

Pois a crença em algo que escape ao dizer parece a princípio depender da crença na visão da linguagem como um sistema de representação, como algo que existe de alguma forma em algum

em suas reflexões sobre o comum-estranho, ambos os autores exploram confluências entre as escritas de Wittgenstein e de Beckett.

${ }^{4}$ Parecem concordar quanto a isso importantes leitores que, sob outros aspectos, discordam bastante, tais como Peter Hacker, Cora Diamond, Luiz Henrique Lopes dos Santos, entre muitos outros. 
lugar: em separado. E é, como revimos, justamente essa visão de linguagem que Wittgenstein busca recusar em sua segunda filosofia, nisso aproximando-se de Beckett. Se a linguagem não é mais contígua ao que quer que seja, se ela é somente práxis, se não tem adjacências, se mantêm com o mundo e a vida laços mutuamente constitutivos, se não há enfim um dentro e um fora da linguagem, o que então poderia ainda escapar à linguagem - mostrar-se, por assim dizer, no seu limite? Diante disso, muitos concluíram: para o segundo Wittgenstein, não há mais um indizível, nada mais se oculta da/na linguagem, nada mais se mostra sem se dizer.

Tenho explorado, em menor companhia, um outro caminho: parece-me que uma tensão ou um jogo entre dizer e mostrar sobrevive na segunda escrita de Wittgenstein. ${ }^{5}$ Claro está que não há mais lugar nessa escrita para a indicação de um inefável compreendido como regiāo ignorada, como um espaço exterior que ultrapassaria as fronteiras da linguagem: pois a linguagem agora, já se disse, não se limita por nada, não é o exterior de qualquer interior oculto, não se estende até a beira de qualquer fora inefável. No entanto, parecem diluir a força da escrita de Wittgenstein as (muitas) leituras que de alguma forma insistem ainda em compreender a própria linguagem dita comum como um espaço pacífico, igual a si mesmo, sem surpresas, desde que devidamente protegido das investidas doentias dos filósofos profissionais. Marjorie Perloff adverte contra esse tipo de leitura quando insiste que "o ordinário de Wittgenstein é melhor compreendido simplesmente como aquilo que é, a linguagem que de fato usamos", podendo perfeitamente, nesse sentido, ser fantástico, misterioso, incompreensível - estranho.*

Se resistimos à propensão de trivializar o comum, o lema "nada está oculto", tal como o "nada a expressar" de Beckett, poderá ser lido menos como declaração e mais como ação - talvez como uma espécie de "cutucão" ou lembrete: repare como o comum acomoda o imprevisível, o fantástico e estranho a si mesmo; veja e se possível viva isso que paradoxalmente se oculta sem estar oculto, que se esconde mesmo quando bem debaixo do nariz. Sobre isso, talvez esteja certo Stanley Cavell, para quem, em Wittgenstein, o comum não é um dado, mas uma sempre renovada tarefa. Para o autor, a insistência em dar a ver e a experimentar um comum-estranho

\footnotetext{
${ }^{5}$ Ver sobre isso: MARTINS, Helena e EL-JAICK, Ana Paula G. “Tem certeza?”. In: L. Levy; L. C. Pereira; M. Zingano. (Orgs.). Metafisica, lógica e outras coisas mais. Rio de Janeiro: Nau Editora, 2012, p. 134-155.
} 
* (CAVELL, Stanley. "The uncanniness of the ordinary": 87 et seq.)

* (BLANCHOT, Maurice. L'Amitié. Paris: Gallimard, 1971: 71.) que é insuperável, irredutível e inexplicável distinguiria as inflexões de Wittgenstein - e de Beckett - daquelas de outros importantes nomes ligados à temática do estranhamento, notadamente Freud.* Seja como for, se a linguagem é para Wittgenstein antes de mais nada práxis, forma de vida, sua escrita será então, ela mesma, performática: não será, sob esse ângulo, a mera descrição de um comum hipostasiado, mas antes um agir que busca realizar, entre outras coisas, essa tarefa do comum.

Tomada, além disso, como ato de literatura, ${ }^{6}$ a escrita-ação de Wittgenstein tem uma virtude mostrativa que não mais se compreende como dicotômica em relação ao plano do dizer. Wittgenstein parece de fato honrar o que Blanchot, em palavras que soam bastante contemporâneas, nos disse certa vez sobre o devir das línguas na literatura: a literatura afirma, para o autor, "tudo o que uma língua contém de futuro num momento particular, tudo nela convoca ou indica um estado que é outro, por vezes perigosamente outro".* $\mathrm{O}$ ato literário como performance - não mais como (apenas) expressão ou descrição de uma realidade, um pensamento, um estado anímico etc. - mostraria assim o estranho no comum, o fora no dentro: e o próprio mostrar no dizer.

Ignorando o imperativo de Wittgenstein sobre a filosofia como "composição poética", dichten - e seu convite a perceber também o próprio Dichten como práxis-, muitos de seus leitores empobreceram a sua língua comum, ao decretarem que não haveria mais lugar nela para o jogo entre dizer e mostrar. Creio, ao contrário, que a escrita de Wittgenstein, como a de Beckett, sem evocar ou aspirar mais um inefável puro e invulnerável à linguagem, dão ainda assim testemunho de um inexplicável, de um incompreendido.

O comum de Wittgenstein e o absurdo de Beckett, se percebidos como versóes simétricas de uma mesma espécie de lucidez final, debilitam-se - tomá-los assim é talvez ceder à vontade de "solução" a que ambos tanto se empenharam em resistir. Um comum paradoxalmente estranho que insiste em suas escritas promete deter essa propensão.

Nos textos dos dois autores encontramos ocasião para experimentar esse comum-estranho - efeito que talvez estivesse afinal no

\footnotetext{
${ }^{6}$ Para um breve inventário das muitas outras ocasiōes, além daquela já citada aqui, em que ouvimos Wittgenstein proclamar seu interesse em unir o filosófico e o poético, ver MARTINS, H. "A escrita poética de Wittgenstein, sua tradução". In: Revista Brasileira de Literatura Comparada, n. 19, 2011.
} 
horizonte do obsessivo trabalho textual que, segundo informam os biógrafos, marcou os ofícios de Beckett e de Wittgenstein. Pouco ou nada há de deliberadamente aleatório nas quebras abruptas, na confusão das vozes, na reticência sonegadora das perguntas, na frequência do tom infantil (o rei está nu), na oscilação indecisa e provocativa entre o literal e o metafórico, nas afirmaçōes retumbantes ironizadas mas nunca inteiramente descartadas, nas alusões vagas, nas composiçôes fragmentárias e descontínuas - enfim nada parece gratuito nessas e em outras características que, flagrando-se com formas e ênfases distintas nas escritas dos dois autores, tornam-nas a um tempo comuns e estranhas. Bagunçam-nas, diríamos com Beckett, mas fazem-no de forma a deter, se possível, o impulso de forjar explicaçôes que as possam assear: "[a] confusão não é invenção minha", ele nos diz, "não se pode escutar uma conversa por cinco minutos sem se dar conta dessa confusão"; Beckett nos diz, instando-nos a "deixá-la entrar" - "[a] única chance de renovação é abrir os olhos e ver a bagunça; não é uma bagunça que possa ser explicada."*

Trago agora, para fechar de forma deliberadamente aberta este texto, algumas passagens de Wittgenstein e de Beckett que, a meu ver, sublinham no comum essa sua bagunça estranha, sem explicação. São exemplos escolhidos entre muitos outros de forma um tanto aleatória, mas que reúno aos pares, não apenas pela (surpreendente) afinidade, mas também para reforçar a fertilidade que suponho haver em uma escuta conjunta das duas vozes.

1

Senhor guarda, ele gritou, Deus é testemunha, ele estava com a mão bem ali.

Deus é uma testemunha que não pode prestar juramento.*

Que é que sentiríamos se não tivéssemos ouvido falar de Cristo?

Sentir-nos-íamos abandonados, sozinhos no escuro? Fugiremos a tal sensação da mesma maneira, simplesmente, que uma criança lhe foge quando sabe que está alguém com ela no quarto?*

\section{2}

Tente agora me pôr para fora, eu disse. Eu só devo ter compreendido o sentido dessas palavras, e mesmo do pequeno ruído que elas produziram, alguns segundos depois de pronunciá-las. Eu estava tão desabituado a falar, que minha boca às vezes se abria, por sua própria conta, deixando escapar frases impecáveis do ponto de vista gramatical, mas inteiramente desprovidas, não direi de sentido, pois ao examiná-las bem elas tinham um e às vezes vários sentidos,
* (BECKETT, Samuel. Entrevista a Tom Driver. In: Samuel Beckett: The Critical Heritage. Graver, L. e Federman, R. (eds.). London: Routledge, 1997: 242.)

\footnotetext{
* (BECKETT, Samuel. Watt. In: Samuel Beckett: The Grove Centenary Edition. Paul Auster (org), vol. I, New York: Grove Press, 2006: 172.)

* (WITTGensteIN, Ludwig. Cultura e valor. Trad. J. Mendes, Lisboa: Edições 70, 1996: 29.)
} 
(BECKETT, Samuel. First Love. In: Samuel Beckett: the Complete Short Prose - 1929-1989, New York: Grove Press: 41.)

(WITTGENSTEIN, Ludwig. Da certeza. Trad. Maria E. Costa. Lisboa: Edições 70, 1969: §244.)

(BECKETT, Samuel. Molloy. Trad. Ana Helena Souza. São Paulo: Globo, 2007: 32.)

(WITTGENSTEIN, Ludwig. Da certeza, op. cit.: §7.)

(BECKETT, Samuel. O inominável. Trad. Maria J. V. de Figueiredo. Lisboa: Assírio \&. Alvim, 2002: 11.)

(WITTGENSTEIN, Ludwig Investigações Filosóficas Trad. José C. Bruni. São Paulo: Nova Cultural, 1999: $\S 71$. mas de fundamento. Mas eu ouvia cada uma das palavras, tão logo eram pronunciadas.*

Se alguém diz: "Eu tenho um corpo", pode perguntar-se-lhe: "Quem está a falar aqui com esta boca?"*

3

Tirei meu chapéu e olhei para ele. Um cadarço comprido amarra-o, desde sempre à minha botoeira, sempre a mesma, qualquer que seja a estação. Logo, ainda estou vivo. É bom saber.*

A minha vida mostra que sei ou que estou certo de que há uma cadeira ali, ou uma porta, etc. Digo a um amigo, por exemplo, "Sente-se naquela cadeira", "Feche a porta", etc. etc.*

4

Aqui tudo é claro. Não, nem tudo é claro. Mas o discurso tem de ser feito. E inventam-se escuridóes. Pura retórica. O que é que essas luzes a que não peço que tenham nenhum significado preciso, terão de tão estranho, de tão deslocado?*

Não é a imagem pouco nítida justamente aquela de que, com frequência, precisamos?*

Mobilizando temas clássicos como o lugar da religião nos assuntos humanos, o mistério da voz, a insistência do desvão entre corpo e espírito, a experiência da dúvida radical, a aspiração pela clareza superlativa, essas passagens resistem no entanto a se apaziguar em teses ou explicações: soluções. Tornando-se, como sugere a etimologia de dichten, espessas, densas - mas recusando-se, ao mesmo tempo, a dar às palavras um compartimento ontológico específico, a abstraí-las da vida -, são escritas que, entre muitas outras coisas, dizem-mostram um estranho: contaminam reciprocamente o dizer e o mostrar sublinhando sua natureza igualmente performática. E isso em um plano que, em certo sentido, promete resistir à intelecção. O estranho, o inexplicável, o incompreendido não são agora descritos - não mais convocam revelações, pois nada está oculto, ou se reduzem a expressões, pois nada a expressar: deixam-se reconhecer no comum, sem se deixar compreender.

E reconhecer no comum o estranho não é aqui torná-lo conhecido: com sorte, é, muito ao contrário, uma ocasião para nele persistir - experimentar seus riscos, suas oportunidades.

Helena Martins é professora do Departamento de Letras da PUC-Rio e pesquisadora bolsista de produtividade do CNPq, nível 2. Publicou, entre outros, os seguintes textos: "O Chapéu de Beckett" (Gragoatá, no. 26, 2009), "Wittgenstein, the body, its metaphors" (DELTA, no. 26, Spe- 
cial issue, 2010); "Beckett e a língua dos outros: que outros?" (Tradução em Revista, 7, 2009); "A escrita poética de Wittgenstein, sua tradução" (Revista da Abralic, no. 19, 2012); "Poeira de verbo" (publicado em Literatura e criatividade, H. K. Olinto e K. E. Schøllhammer (orgs.), 7Letras, 2012). E-mail: <lena@puc-rio.br> 